\title{
Crafting Normative Messages to Protect the Environment
}

\author{
Robert B. Cialdini ${ }^{1}$ \\ Department of Psychology, Arizona State University, Tempe, Arizona
}

\begin{abstract}
It is widely recognized that communications that activate social norms can be effective in producing societally beneficial conduct. Not so well recognized are the circumstances under which normative information can backfire to produce the opposite of what a communicator intends. There is an understandable, but misguided, tendency to try to mobilize action against a problem by depicting it as regrettably frequent. Information campaigns emphasize that alcohol and drug use is intolerably high, that adolescent suicide rates are alarming, and - most relevant to this article - that rampant polluters are spoiling the environment. Although these claims may be both true and well intentioned, the campaigns' creators have missed something critically important: Within the statement "Many people are doing this undesirable thing" lurks the powerful and undercutting normative message "Many people are doing this." Only by aligning descriptive norms (what people typically do) with injunctive norms (what people typically approve or disapprove) can one optimize the power of normative appeals. Communicators who fail to recognize the distinction between these two types of norms imperil their persuasive efforts.
\end{abstract}

Keywords

norms; environment; public service announcements

It is rare when a public service announcement (PSA) is believed to have the sort of effectiveness achieved by the most successful mass media commercial messages, which typically benefit from much larger production budgets and broadcast frequencies. Yet there is one PSA that is regularly credited as having such status. Called the "Iron Eyes Cody spot" (after the Native American actor who starred in it), it begins with a shot of a stately, buckskin-clad American Indian paddling his canoe up a river that carries various forms of industrial and individual pollution. After coming ashore near the littered side of a highway, the Indian watches as a bag of garbage is thrown, splattering and spreading along the road, from the window of a passing car. From the refuse at his feet, the camera pans up slowly to the Indian's face, where a tear is shown tracking down his cheek, and the slogan appears: "People Start Pollution, People Can Stop It."

Broadcast for many years in the 1970s and 1980s, the spot won numerous awards and millions upon millions of dollars of donated airtime. Indeed, it has even been named the 16th best television commercial of all time by TV Guide magazine ("The Fifty Greatest," 1999). However, despite the fame of this touching piece of public service advertising, research suggests that it contains features that may be less than optimal, and perhaps even negative, in their impact on the littering actions of those who see it. In addition to the laudable message in the ad urging viewers to stop littering, there is the underlying message, as well, that a lot of people do litter: Debris floats on the river, litter lies at the roadside, trash is tossed from an automobile. 


\section{DESCRIPTIVE VERSUS INJUNCTIVE NORMS}

Thus, the creators of the Iron Eyes Cody spot may well have pitted two kinds of norms against one another, injunctive norms (involving perceptions of which behaviors are typically approved or disapproved) and descriptive norms (involving perceptions of which behaviors are typically performed). Much research indicates that both kinds of norms motivate human action; people tend to do what is socially approved as well as what is popular. The wisdom of setting these two kinds of motivations in line with (rather than in opposition to) one another within a communication has direct implications for the development of pro-environmental messages. Experiences that focus individuals on the all-too-frequent occurrence of an offense against the environment have the potential to increase the occurrence of that offense.

\section{An Initial Experiment}

To explore this possibility as it applies to individuals' decisions to despoil the environment, my colleagues and I have conducted a variety of studies over the past several years. In one investigation (Cialdini, Reno, \& Kallgren, 1990, Experiment 1), participants were given the opportunity to litter (a handbill they found on their car windshields) into either a previously clean or a fully littered environment after first witnessing a confederate who either dropped trash into the environment or simply walked through it. By varying the state of the environment (clean vs. littered), we sought to manipulate the perceived descriptive norm for littering in the situation. By manipulating whether the confederate dropped trash into the environment, we sought to differentially focus participants' attention on the state of the environment and, consequently, to manipulate the salience of the perceived descriptive norm there (i.e., what most people did).

We had three main predictions. First, we expected that participants would be more likely to litter into an already littered environment than into a clean one. Second, we expected that participants who saw the confederate drop trash into a fully littered environment would be most likely to litter there themselves, because they would have had their attention drawn to evidence of a pro-littering descriptive norm - that is, to the fact that people typically litter in that setting. Conversely, we anticipated that participants who saw the confederate drop trash into a clean environment would be least likely to litter there, because they would have had their attention drawn to evidence of an anti-littering descriptive norm - that is, to the fact that (except for the confederate) people typically do not litter in that setting. This last expectation distinguished our normative account from explanations based on simple modeling processes in that we were predicting decreased littering after participants witnessed a model litter.

As can be seen in Figure 1, the data supported our experimental hypotheses. Overall, there was more littering in the littered environment than in the clean environment. In addition, the most littering occurred when participants saw a model drop trash into a littered environment; and, most tellingly, the least littering occurred when participants saw a model drop trash into a clean environment. 


\section{Rethinking the Iron Eyes Cody PSA}

At this point, it is appropriate to look back at the Iron Eyes Cody PSA, as the findings of our study point to reasons for concern about the effectiveness of that ad. Recall that it depicts a character who sheds a tear after encountering an array of litter. No doubt the tear is a powerful reminder of the injunctive norm against littering in U.S. culture. But accompanying the beneficial reminder is the potentially damaging message that many people $d o$ litter. Thus, the resultant impact of the injunctive norm against littering may be undermined by the unintended presentation of a descriptive norm for littering. Moreover, that presentation occurs in a way that, according to the results of our study, may be especially damaging. That is, the creators of the ad seem to have been correct in their decision to show a dismaying instance of someone (the passing motorist) actively littering the environment; but they may have been mistaken in their decision to use an already-littered environment, as the observation of another person littering into a littered environment produced the greatest littering in our study. In contrast, the combination of a (single) litterer and an otherwise clean environment generated the least littering from our participants.

Were we to suggest a revision of the Iron Eyes Cody PSA, then, it would be to make the procedurally small but conceptually meaningful modification of changing the depicted environment from trashed to clean - and thereby changing the perceived descriptive norm regarding littering. Then, when the disapproving tear appeared, viewers would be exposed to injunctive and descriptive norms guiding behavior in the same direction.

\section{ENVIRONMENTAL THEFT}

In situations already characterized by high levels of socially censured conduct, the distinction between descriptive and injunctive norms offers a clear implication: It is a serious error to focus an audience on the descriptive norm (i.e., what is done in those situations); instead, public service messages should focus the audience on the injunctive norm (i.e., what is approved or disapproved in those situations). Take, for instance, the case of Arizona's Petrified Forest National Park, which suffers from the estimated theft of more than a ton of wood per month by visitors. New arrivals quickly learn of the past thievery from prominently placed signage: "Your heritage is being vandalized every day by theft losses of petrified wood of 14 tons a year, mostly a small piece at a time."

Although it is understandable that park officials would want to instigate corrective action by describing the dismaying size of the problem, such a message ought to be far from optimal. According to an informed normative account, it would be better to design park signage to focus visitors on the social disapproval (rather than the harmful prevalence) of environmental theft. Recently, my colleagues and I sought to examine this hypothesis - that in a situation characterized by unfortunate levels of socially disapproved conduct, a message that focuses recipients on the injunctive norm will be superior to messages that focus recipients on the descriptive norm (Cialdini et al., 2003).

To test our expectation, we gained permission from Petrified Forest National Park officials to place secretly marked pieces of petrified wood along visitor pathways. During five consecutive weekends, at the entrance to each path, we displayed signage that 
emphasized either descriptive or injunctive norms regarding the theft of petrified wood from the park. The descriptive-norm sign stated, "Many past visitors have removed petrified wood from the Park, changing the natural state of the Petrified Forest." This wording was accompanied by pictures of three visitors taking wood. In contrast, the injunctive-norm sign stated, "Please don't remove the petrified wood from the Park, in order to preserve the natural state of the Petrified Forest." This wording was accompanied by a picture of a lone visitor stealing a piece of wood, with a red circle-and-bar symbol superimposed over his hand. Our measure of message effectiveness was the percentage of marked pieces of wood stolen over the 5-week duration of the study. As predicted, the descriptive-norm message resulted in significantly more theft than the injunctive-norm message $(7.92 \%$ vs. $1.67 \%){ }^{2}$

\section{RECYCLING}

Should one conclude from these results that highlighting descriptive norms is always likely to be a counterproductive tactic in environmental information campaigns? No. Although highlighting descriptive norms is detrimental when environmentally harmful behavior is prevalent, this approach should be effective when the prevalent behavior is environmentally beneficial. For example, if the majority of citizens conserve energy at home, campaign developers would be well advised to include such descriptive normative information in their presentations intended to increase residential energy conservation. Of course, if the majority of citizens also approve of such efforts, the campaign developers would be wise to incorporate this injunctive normative information as well.

Thus, the most effective norm-based persuasive approach under these circumstances would be one that enlists the conjoint influence of descriptive and injunctive norms. To examine the impact of an information campaign that combined the influence of injunctive and descriptive norms, my colleagues and I created three PSAs designed to increase recycling, an activity that was both performed and approved by the majority of local residents in our study area. Each PSA portrayed a scene in which the majority of depicted individuals engaged in recycling, spoke approvingly of it, and spoke disparagingly of a single individual in the scene who failed to recycle. When, in a field test, these PSAs were played on the local TV and radio stations of four Arizona communities, a 25.35\% net advantage in recycling tonnage was recorded over a pair of control communities not exposed to the PSAs.

Although a $25 \%$ recycling advantage is impressive from a practical standpoint, that study did not allow for confident theoretical conclusions about the causes of the advantage. For instance, it was not possible to determine the extent to which our PSAs may have been effective because of their normative elements. After all, it is conceivable that the PSAs were successful because they included humorous and informational components unrelated to norms. In order to assess whether and to what degree descriptive and injunctive norms - separately and in combination - contributed to the messages' effectiveness, additional evidence was necessary. To that end, we conducted a study in which college students viewed our three recycling PSAs and rated their impact along several relevant dimensions (Cialdini et al., 2003). 
That study was designed to determine whether our PSAs had the intended effect of conveying to viewers that recycling was prevalent (descriptive norm) and approved (injunctive norm), whether these perceived norms influenced viewers' intentions to recycle, and whether the two types of norms operated similarly or differently to affect recycling intentions. A statistical analysis of the results indicated that both normative and nonnormative factors influenced the intent to recycle (see Fig. 2). Of course, the finding that nonnormative factors (prior attitude, new information, humor) had causal impact is not incompatible with our theoretical position, as we certainly would not claim that normative factors are the only motivators of human responding.

At the same time, it is encouraging from our theoretical perspective that both injunctive and descriptive normative information significantly influenced recycling intentions. That is, as a result of viewing the ads, the more participants came to believe that recycling was (a) approved and (b) prevalent, the more they planned to recycle in the future. It is noteworthy that, despite a strong correlation $(r=.79)$ between participants' perceptions of the existing prevalence and approval of recycling, these two sources of motivation had independent effects on recycling intentions. Such results affirm the theoretical distinction between descriptive and injunctive norms.

\section{CONCLUSION}

Public service communicators should avoid the tendency to send the normatively muddled message that a targeted activity is socially disapproved but widespread. Normbased persuasive communications are likely to have their best effects when communicators align descriptive and injunctive normative messages to work in tandem rather than in competition with one another. Such a line of attack unites the power of two independent sources of normative motivation and can provide a highly successful approach to social influence.

At the same time, certain issues remain to be clarified if communicators are to optimize the impact of norm-based messages. The first concerns the nature of the psychological mechanisms that underlie descriptive and injunctive norms. The results of our last study suggest an intriguing difference between them. Information about social approval or disapproval affected recycling intentions by influencing assessments of the ads' persuasiveness (see Fig. 2). Information about relative prevalence, in contrast, influenced intentions directly, without affecting the perceived persuasiveness of the ads. Why should that be the case? One possibility is that because descriptive norms are based in the raw behavior of other individuals, it is relatively easy to accommodate to such norms without much cognitive analysis. Indeed, organisms with little cognitive capacity do so: Birds flock, fish school, and social insects swarm. Injunctive norms, however, are based in an understanding of the moral rules of the society (i.e., what other people are likely to approve), and should therefore require more cognitive analysis to operate successfully. Hence, one might expect that the impact of injunctive (but not descriptive) normative information would be mediated through cognitive assessments of the quality or persuasiveness of the normative information. Additional work is necessary to test this possibility. 
A second important research issue concerns the problem of diminished salience of the normative message at the time when a targeted behavior is likely to be performed. Often, the message is no longer present when the desired behavior must take place. For example, PSAs are typically radio, television, and print communications that are encountered at times far removed from the opportunities to perform the socially desirable actions that the PSAs promote. A crucial question to be answered by future investigation is how communicators can structure their messages to maximize the likelihood that the motivational components of those messages will be salient at the time for action. Research that identifies persuasive or mnemonic devices for achieving this goal will be of immense benefit to public service communication efforts.

\section{Recommended Reading}

Bator, R.J., \& Cialdini, R.B. (2000). The application of persuasion theory to the development of effective pro-environmental public service announcements. Journal of Social Issues, 56, 527-541.

Kallgren, C.A., Reno, R.R., \& Cialdini, R.B. (2000). A focus theory of normative conduct: When norms do and do not affect behavior. Personality and Social Psychology Bulletin, 26, 1002-1012.

Schultz, P.W. (1999). Changing behavior with normative feedback interventions: A field experiment on curbside recycling. Basic and Applied Social Psychology, 21, 2538.

\section{Notes}

1. Address correspondence to Robert B. Cialdini, Department of Psychology, Arizona State University, Tempe, AZ 85287-1104; e-mail: robert.cialdini@asu.edu.

2. These data are best understood in the context of previous research indicating that the ratio of thefts to park visitors falls just under $3 \%$.

\section{References}

Cialdini, R.B., Barrett, D.W., Bator, R., Demaine, L.J., Sagarin, B.J., Rhoads, K.v.L., \& Winter, P.L. (2003). Activating and aligning social norms for persuasive impact. Manuscript submitted for publication.

Cialdini, R.B, Reno, R.R., \& Kallgren, C.A. (1990). A focus theory of normative conduct: Recycling the concept of norms to reduce littering in public places. Journal of Personality and Social Psychology, 58, 1015-1026.

The Fifty Greatest TV Commercials of All Time. (1999, July 3-9). TV Guide, pp. 2-34. 